\title{
Notch Sensitivity of the Fatigue Limit in High-Strength Steel
}

\author{
Yasuaki HAMANO, ${ }^{1)}$ Motomichi KOYAMA, ${ }^{2)}$ Shigeru HAMADA ${ }^{2)}$ and Hiroshi NOGUCHI ${ }^{2 *}$ \\ 1) Graduate School of Engineering, Kyushu University, 744 Moto-oka, Nishi-ku, Fukuoka, 819-0395 Japan. \\ 2) Department of Mechanical Engineering, Faculty of Engineering, Kyushu University, 744 Moto-oka, Nishi-ku, Fukuoka, 819- \\ 0395 Japan.
}

(Received on January 5, 2016; accepted on April 19, 2016; originally published in Tetsu-to-Hagané, Vol. 101, 2015, No. 10, pp. 552-558)

\begin{abstract}
The fatigue limit of a tempered martensitic steel was evaluated in specimens with stress concentration sources, which were introduced with a small drill and focused ion beam (FIB). In a previous study using ferrite-pearlite steel, the fatigue limit of a specimen with a FIB notch was almost the same as the fatigue limit of a specimen with a drill hole, and the non-propagating cracks were found around both shapes of stress concentration sources. However, the fatigue limit of the specimen with a FIB notch was about 100 $\mathrm{MPa}$ lower than the fatigue limit of the specimen with a drill hole in tempered martensitic steel. Additionally, the non-propagating crack was observed only in the specimen with a FIB notch. The stress concentration source shapes in both materials are the same, then the difference in fatigue limit stems from the material property. This indicates that there is applicable range where stress concentration source is regarded as a pre-crack, and the range depends on material. At first, the reason for the difference in fatigue limit was discussed in terms of the non-propagating crack. In this part, we discussed nonpropagating crack phenomenon around drill hole. Secondly, the effect of hardness which caused the difference in fatigue limit was discussed by using an analytical result of Dugdale model. Finally, we inferred the notch sensitivity from the propagation by deformation at crack tip. After that, we concluded that the propagation by fracture at crack tip is also important factor in analyzing notch sensitivity.
\end{abstract}

KEY WORDS: fatigue limit; notch sensitivity; drill hole; FIB notch; high-strength steel.

\section{Introduction}

Recently, to construct large and light structures, steels of high strength have been sought increasingly. More specifically, their fatigue limit is one of the most important strength properties. In this study, we therefore focus on the fatigue limit as dominated by fatigue crack non-propagation behavior. In order to precisely evaluate and design relative to fatigue limits, we must understand the factors affecting behaviors of fatigue crack initiation, propagation, and nonpropagation. ${ }^{1)}$ In general, the fatigue limit is analyzed with two types of specimen geometry: smooth and notched. A smooth specimen is used to analyze the behavior of fatigue crack growth via fatigue crack initiation, propagation, and non-propagation. ${ }^{2)}$ Meanwhile, a notched specimen is used to analyze the effects of small defects and inclusions. From a practical viewpoint, the behavior of a non-propagating fatigue crack, which is initiated from artificial stress concentration sources such as small defects, is especially important. ${ }^{3)}$

There are several methods to introduce an artificial stress concentration source on the specimen surface. In case annealing does not affect the microstructures of a target material, a fatigue crack is introduced by fatigue testing until a specific fatigue crack length is reached. Next, the

\footnotetext{
* Corresponding author: E-mail: nogu@mech.kyushu-u.ac.jp DOI: http://dx.doi.org/10.2355/isijinternational.ISIJINT-2015-744
}

fatigued specimen is annealed in a vacuum to remove the effects of work hardening near the crack tip. ${ }^{4)}$ However, the same methodology cannot be applied for heat-treatmentsensitive materials such as martensitic steel. ${ }^{5)}$ Annealing in martensitic steels causes reverse transformation to austenite, recrystallization/recovery, and precipitation of carbides, which means that the initial microstructure is changed drastically. In order to avoid the effects of microstructural changes, an artificial stress concentration source such as a small drill hole is introduced to the specimens, instead of a pre-crack introduced by fatigue testing. ${ }^{6}$ In a previous study, a JIS-S45C annealed specimen was tested, and the fatigue limit of a drill-holed specimen was almost same as that of a pre-cracked specimen. ${ }^{7,8)}$ In these experiments, the square root of the projected area of the stress concentration source, $\sqrt{\text { area }}$, was adjusted to be equal to or less than $1 \mathrm{~mm} .{ }^{3)}$ However, there are differences in the stress concentration factor and the area of the zone affected by the stress concentration between the pre-cracked and drill-holed specimens. Thus, the equality of the fatigue limit requires deeper discussion. ${ }^{9)}$

Sakamoto et al. ${ }^{9)}$ evaluated the difference of fatigue limits among ferrite-pearlite steel specimens with a drill hole, focused-ion-beam (FIB) notch, ${ }^{10-12)}$ and a pre-crack in order to study differences between stress concentration source shapes. In this examination, the fatigue limit of the ferritepearlite steel did not depend significantly on the stress concentration source shape. By reference to Sakamoto's work, 
in this study, the fatigue limit of a high-strength, quenched, and tempered martensitic steel is examined to evaluate differences in the fatigue limits among specimens with a drill hole and an FIB notch. High-strength steels, such as martensitic steels, show unique relationships between tensile strengths and fatigue limits ${ }^{13)}$ which are completely different from the features in low-strength steels. This phenomenon is called notch sensitivity. In fact, the fatigue limit of low-strength steels exhibits a clear linear relationship with tensile strength, but that of high-strength steels does not. In fact, even negative tensile strength dependence of the fatigue limit has been observed in high-strength steels. This characteristic tensile strength dependence of the fatigue limit has been considered to stem from sensitivity to the stress concentration. ${ }^{3)}$ More specifically, although a persistent slip band (PSB) is one of the most important causes of fatigue crack initiation in low-strength steels, fatigue crack initiation of high-strength steels occurs from stress concentration sources such as small inclusions. This distinct difference has been considered to explain the characteristic tensile strength dependence of fatigue limits in high-strength steels. However, the interpretation of the notch sensitivity of the fatigue limit in high-strength steels is still phenomenological; therefore, prediction methodology for dependence of the fatigue limit on the test-condition in high-strength steels has not yet been established. Hence, this paper aims to propose a physical explanation of the notch sensitivity based on experimental facts using an approach involving the plasticity-induced crack closure phenomenon.

\section{Experimental Procedure}

The material used for this study was JIS-S45C in the form of a rolled bar with a diameter of $19 \mathrm{~mm}$, which is the same base steel used in Sakamoto's work. ${ }^{9)}$ Table 1 lists its chemical composition. After cutting the specimen to $10 \mathrm{~mm}$ in diameter and $62 \mathrm{~mm}$ in length, quenching and tempering were performed. Table 2 lists the heat treatment conditions used. ${ }^{14,15)}$ Henceforth, the quenched and tempered specimen is called $\mathrm{S} 45 \mathrm{C}(\mathrm{QT})$ and the annealed specimen is called $\mathrm{S} 45 \mathrm{C}(\mathrm{A})$. The hardness, which is correlated with the fatigue limit, ${ }^{3)}$ was tested using a Vickers hardness tester. The Vickers hardness was measured on the mechanically polished surface at a load of $1.96 \mathrm{~N}$ with a holding time of 15 seconds. The hardness was determined as the average of 5 data points. In order to observe the heat treated microstructure, the specimen was mechanically polished with emery paper and colloidal silica. Next, the specimen surface was etched by 3\% Nital. As shown in Fig. 1, the solution-treated

Table 1. Chemical composition (wt.\%).

\begin{tabular}{ccccccc}
\hline $\mathrm{C}$ & $\mathrm{Si}$ & $\mathrm{Mn}$ & $\mathrm{P}$ & $\mathrm{S}$ & $\mathrm{Al}$ & $\mathrm{Fe}$ \\
\hline 0.46 & 0.20 & 0.73 & 0.029 & 0.017 & 0.018 & bal. \\
\hline
\end{tabular}

Table 2. Heat treatment condition and Vickers hardness.

\begin{tabular}{ccc}
\hline Material & Heat treatment & HV \\
\hline S45C & Annealing $845^{\circ} \mathrm{C}, 1$ hr water quench & 510 \\
& $\rightarrow$ Tempered $200^{\circ} \mathrm{C}, 1$ hr water quench & \\
\hline
\end{tabular}

microstructure is that of tempered martensite.

After heat treatment, fatigue specimens were prepared using a lathe. Figure 2 shows the specimen geometry. For comparison with the previous results, the stress concentration source shapes were designed to be the same as the shapes of Sakamoto's report. ${ }^{9}$ The test section of the specimens were first ground by \#280-\#2000 emery papers and then polished by a buff with $1-\mu \mathrm{m}$ diameter alumina particles. Subsequently, the specimen was electrochemically polished at $60^{\circ} \mathrm{C}$ and $12 \mathrm{~V}$ in a solution of phosphoric acid (2 $000 \mathrm{~mL})$, oxalic acid (40 g), and gelatin (40 g). Finally, a drill hole or FIB notch was introduced in the central part of each specimen. The drill holes were set to be $100 \mu \mathrm{m}$ in diameter and $47 \mu \mathrm{m}$ in depth. During the drilling process, the contact point between the drill and the specimen was detected electrically, and the depth of the drill holes was determined by a dial gauge. The accuracy of the depth measurement was $\pm 2 \mu \mathrm{m}$. FIB notches were introduced by using an FEI Quanta 3D 200i at $30 \mathrm{kV}$ and $15 \mathrm{nA}$. The FIB notch geometry is shown in Fig. 3. The area values of both stress concentration sources were adjusted so that $\sqrt{\text { area }}$ was $57 \mu \mathrm{m}$.

All fatigue tests were performed using an Ono-type rotating/bending fatigue-testing machine at $60 \mathrm{~Hz}$ in air at room temperature. In this experiment, the nominal stress was defined as nominal bending stress in the minimumdiameter zone without considering the effects of the stress concentration source shape. Observations of fatigue crack growth behavior and measurements of fatigue crack length were carried out through the plastic replica technique. The replication was conducted after immersing acetyl cellulose replica film into methyl acetate in a no-load condition. Replica images were taken by optical microscopy.

\section{Results}

Figure 4 shows a diagram of stress amplitude versus the number of cycles to failure $(S-N)$ in the drill-holed

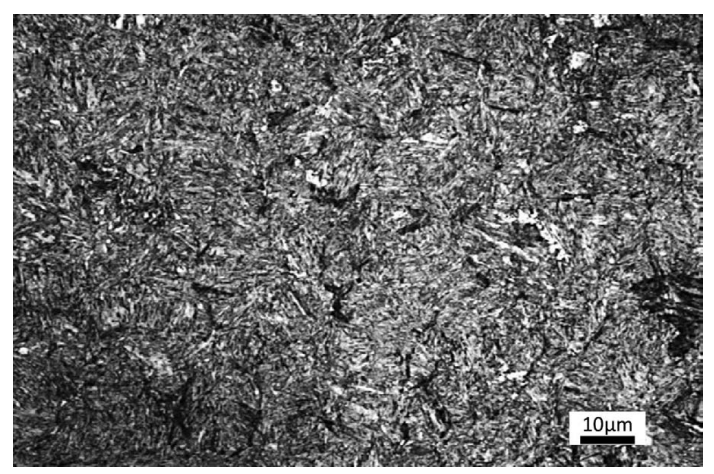

Fig. 1. Optical micrograph showing undeformed microstructure.

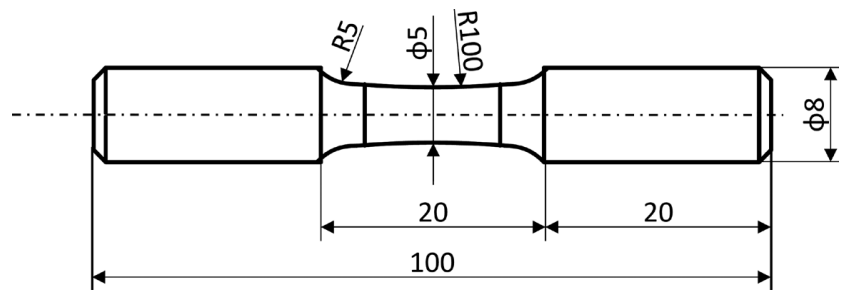

Fig. 2. Shape and dimension of the specimen [unit: $\mathrm{mm}$ ]. 
and FIB-notched S45C(QT) specimens. For comparison, Sakamoto's results for $\mathrm{S} 45 \mathrm{C}(\mathrm{A})^{9)}$ are also plotted in Fig. 4. As shown in Fig. 4, the fatigue limit of the S45C(QT) drillholed specimen was more than $100 \mathrm{MPa}$ higher than that of the FIB-notched specimen although there is no fatigue limit difference for S45C(A). The replica image around the stress concentration source after $10^{7}$ cycles is shown in Fig. 5. Since a non-propagating fatigue crack is not observed in Fig. 5(a), the fatigue limit of S45C(QT) with a drill hole is determined by the fatigue crack initiation limit $\left(\sigma_{\mathrm{w} 1}\right){ }^{16)}$ Meanwhile, the fatigue limit of S45C(QT) is determined by the fatigue crack non-propagating limit $\left(\sigma_{\mathrm{w} 2}\right)^{16)}$ because a non-propagating fatigue crack appears around the FIB notch in Fig. 5(b). On the other hand, the results for S45C(A) show that the fatigue limit does not depend on the geometry

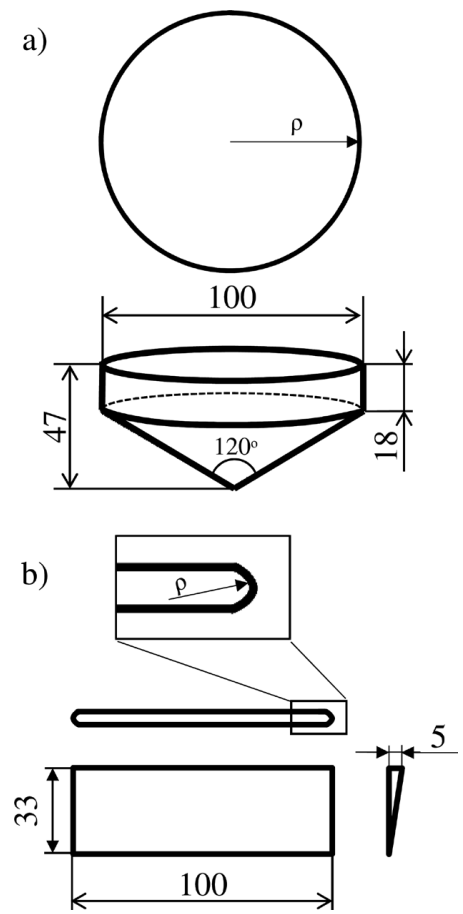

Fig. 3. Shape and dimension of the stress concentration sources having the same Varea size. a) Drill hole b) FIB notch [unit: $\mu \mathrm{m}] \rho$ : radius of curvature of stress concentration source.

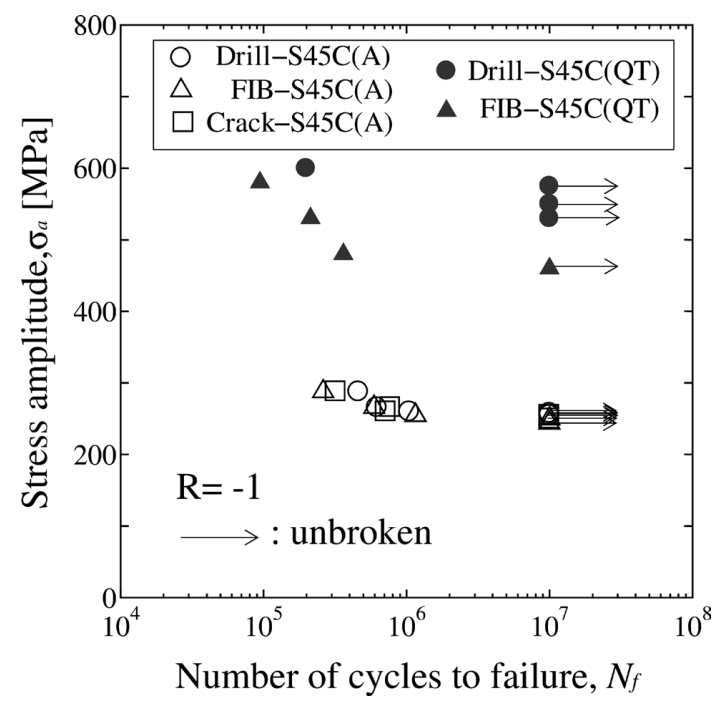

Fig. 4. Relationship between stress amplitude $\sigma_{a}$ and the number of cycles to failure $N_{f}$. of pre-existing defects, whether a drill hole, FIB notch, or pre-crack. In addition, non-propagating fatigue cracks have been reported in all types of specimens. ${ }^{9}{ }^{9}$ Namely, in the present dataset, only S45C(QT) with the drill hole did not show a non-propagating fatigue crack. Henceforth, we discuss factors causing the difference in fatigue crack behavior at the fatigue limits between S45C(QT) and S45C(A).

\section{Discussion}

\subsection{Definition and Problems of $\sigma_{\mathrm{w} 1}$ and $\sigma_{\mathrm{w} 2}$}

Maximum stress in the vicinity of a stress concentration source, $\sigma_{S C}$, is defined as

$$
\sigma_{s c}=K_{t} \sigma_{\infty}
$$

where $\sigma_{\infty}$ is remote stress and $K_{\mathrm{t}}$ is the stress concentration factor. ${ }^{17)}$ In case of an elliptical hole in an infinite plate, $K_{t}$ is determined by

$$
K_{t}=1+2 \sqrt{t / \rho}
$$

where $t$ is the half-length of the stress concentration source and $\rho$ is the curvature radius. ${ }^{17)}$ In addition, the stress-concentration-affected zone originating from a stress concentration source has been known to decrease with increasing degree of stress concentration. ${ }^{18)}$

Figure 6 shows a schematic of the relationship between
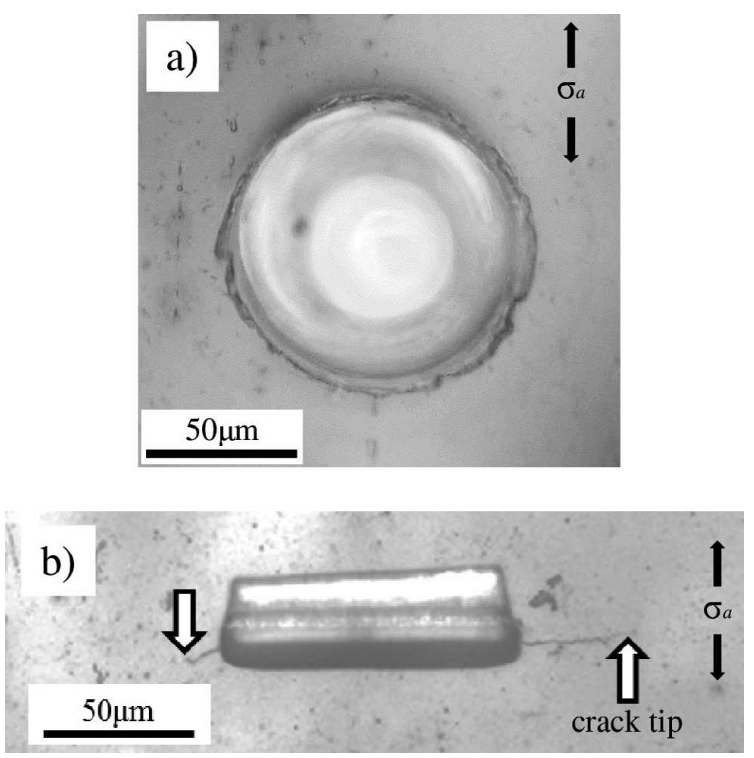

Fig. 5. Replica images showing surface of the specimen near the stress concentration source after $10^{7}$ cycles. a) Drill hole $\left.\left(\sigma_{a}=575 \mathrm{MPa}\right) \mathrm{b}\right)$ FIB notch $\left(\sigma_{a}=460 \mathrm{MPa}\right)$.

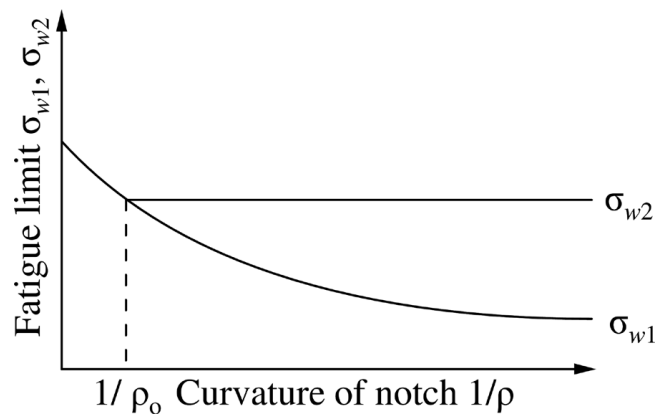

Fig. 6. Relationship between fatigue limit and curvature of notch $1 / \rho$. 
the fatigue limit and $\rho .^{16)}$ In general, $\sigma_{\mathrm{w} 1}$ and $\sigma_{\mathrm{w} 2}$ are regarded as fatigue limits without and with a non-propagating fatigue crack, respectively. More essentially, $\sigma_{\mathrm{w} 1}$ and $\sigma_{\mathrm{w} 2}$ are defined as fatigue limits that depend on the curvature radius of the stress concentration source. As seen in Fig. $6, \sigma_{\mathrm{w} 2}$ is independent of the curvature radius of the stress concentration source. In previous studies, the main factors affecting fatigue crack non-propagation behavior have been reported as a simple summation of the stress concentration source size and fatigue crack length rather than shape of the stress concentration source. ${ }^{19)}$ Namely, as long as the fatigue limit is regarded as $\sigma_{\mathrm{w} 2}$, the effect of an artificial stress concentration source is equivalent to that of a precrack. However, even in the region of $\sigma_{\mathrm{w} 1}$ in Fig. 6 (in other words, the region where the fatigue limit depends on the curvature radius of the stress concentration source), a small non-propagating fatigue crack is rarely observed. ${ }^{20,21)}$ These facts indicate that there is a more intrinsic factor defining $\sigma_{\mathrm{w} 1}$ and $\sigma_{\mathrm{w} 2}$ rather than the presence of a non-propagating fatigue crack. Hence, in this study, we first discuss the intrinsic meanings of $\sigma_{\mathrm{w} 1}$ and $\sigma_{\mathrm{w} 2}$.

\subsection{Definitions of $\sigma_{\mathrm{w} 1}$ and $\sigma_{\mathrm{w} 2}$}

Figure 7 schematically shows the geometries of the non-propagating fatigue cracks for $\sigma_{\mathrm{w} 1}$ and $\sigma_{\mathrm{w} 2} .{ }^{19)}$ When the fatigue limit corresponds to $\sigma_{\mathrm{w} 2}$, the fatigue crack non-

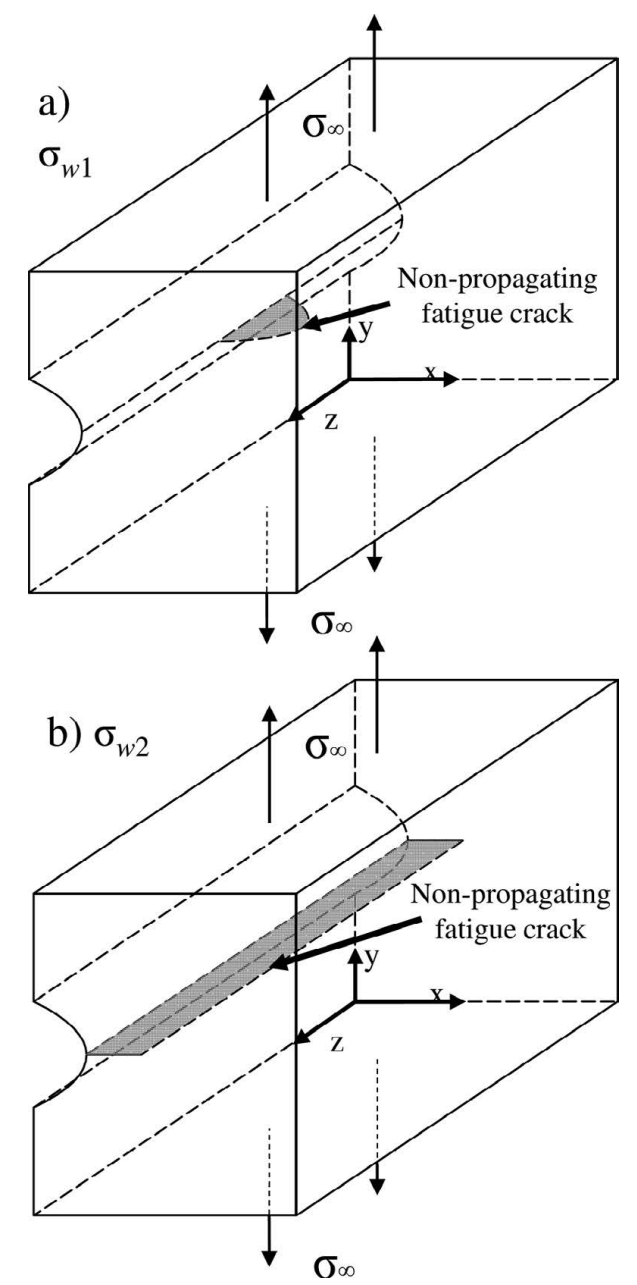

Fig. 7. Schematic diagrams of non-propagating crack around stress concentration source a) $\sigma_{\mathrm{w} 1}$, b) $\sigma_{\mathrm{w} 2 .}{ }^{21)}$ propagation phenomenon is dominated by the behavior of fatigue crack opening and closing. Therefore, the curvature radius of the stress concentration source does not affect the fatigue limit. However, this consideration includes an assumption that the fatigue crack length is larger than the stress-concentration-affected zone arising from the artificial stress concentration source. More specifically, as schematically shown in Fig. 8(a), $\sigma_{\mathrm{w} 2}$ is defined as the "fatigue limit dominated by fatigue crack non-propagation arising from the stress concentration of the fatigue crack independent of the stress concentration of the artificial stress concentration source." In this context, $\sigma_{\mathrm{w} 1}$ is defined as the "fatigue limit dominated by fatigue crack non-propagation under the influence of stress concentration originating from the artificial stress concentration source"22) or the "fatigue limit dominated by fatigue crack initiation"23) (Fig. 8(b)). In this paper, the intrinsic phenomenon controlling the fatigue limit of $\sigma_{\mathrm{w} 1}$ is regarded as the same as that of $\sigma_{\mathrm{w} 2}$. In other words, both $\sigma_{\mathrm{w} 1}$ and $\sigma_{\mathrm{w} 2}$ are determined by the fatigue crack non-propagation phenomenon. Thus, here we discuss the $\sigma_{\mathrm{w} 1}$ where "fatigue crack non-propagation occurs under an influence of the stress concentration originating from the stress concentration sources."

Fatigue crack non-propagation is explained by the fatigue crack closure phenomenon. ${ }^{24)}$ Namely, when an initial crack is ideally sharp, it propagates through plastic deformation associated with crack opening and closing during fatigue cycles. A specific amount of plastic strain remains behind
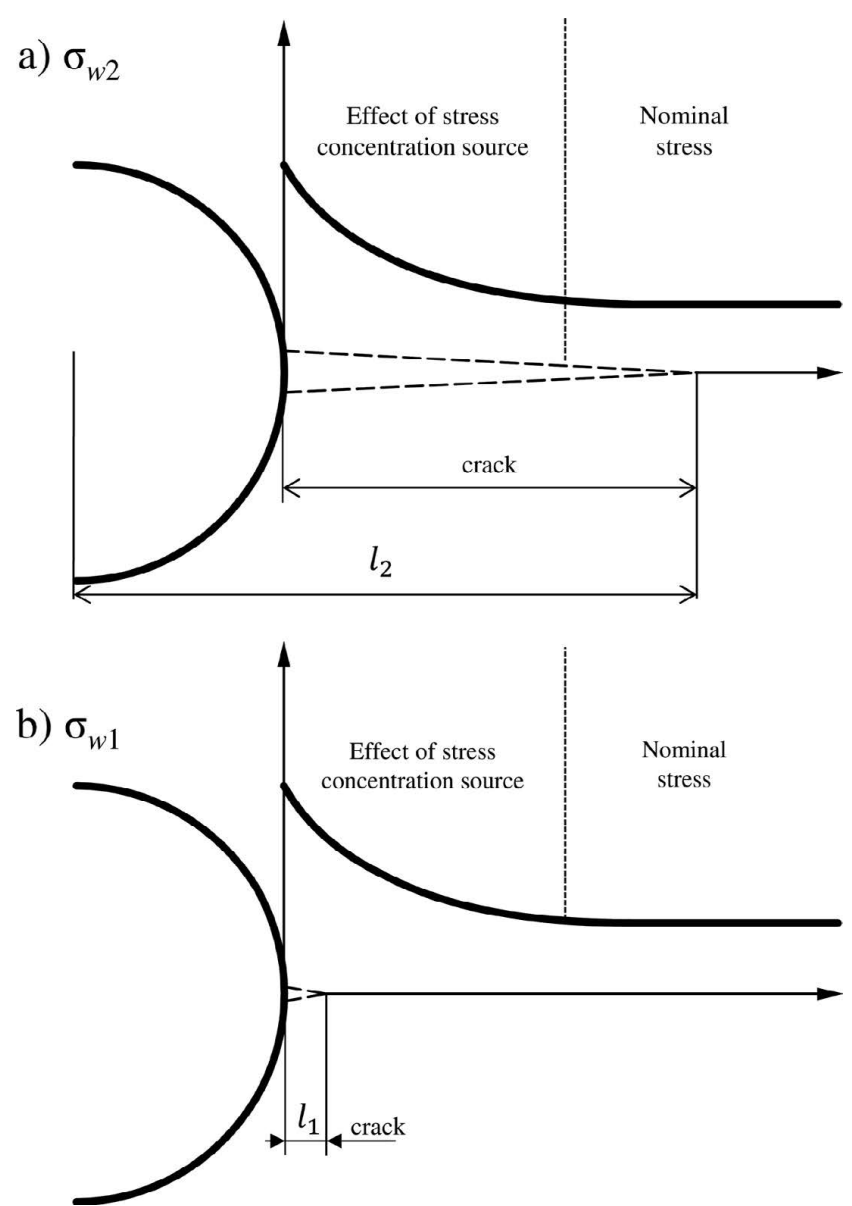

Fig. 8. Non-propagating crack length in the fatigue limit determined by a) $\sigma_{w 2}$, b) $\sigma_{w 1}$. 
the crack tip, decreasing the effective stress applied on the crack. The decrease in effective stress decelerates fatigue crack propagation, and finally the fatigue crack stops propagating. In case of fatigue crack propagation tests using compact tension tests, the threshold stress intensity factor range $\Delta K_{\text {th }}$ is measured as a stress intensity factor range $\Delta K$, where fatigue cracks stop propagating. However, in fact, $\Delta K_{\text {th }}$ for pre-cracked specimens is defined as $\Delta K$ calculated from initial crack length and stress amplitude at the fatigue limit. ${ }^{25)}$ The primary reason for this definition of $\Delta K_{\text {th }}$ is the dependence of non-propagating fatigue crack length on the initial crack length. Because of the initial crack length dependence, fatigue resistance cannot be comprehensively designed based on non-propagating fatigue crack length. Thus, $\Delta K_{\text {th }}$ for a small crack is defined by correlation with the initial crack length. ${ }^{25,26)}$ Therefore, the definition of initial crack length is crucial when discussing fatigue crack non-propagation behavior. As indicated in the previous section, in case the fatigue limit corresponds to $\sigma_{\mathrm{w} 2}$, the effect of the stress concentration source is equivalent to that of a pre-crack. Namely, as shown in Fig. 8(a), the non-propagating fatigue crack length for $\sigma_{\mathrm{w} 2}$ is $l_{2}$, and the initial crack length $l_{\mathrm{w} 2}$ is the size of the pre-existing stress concentration source. In contrast, when the fatigue limit corresponds to $\sigma_{\mathrm{w} 1}$, the stress concentration source contributes only for stress increments in its vicinity. The non-propagating fatigue crack length for $\sigma_{\mathrm{w} 1}$ does not include the size of the stress concentration source $\left(l_{1}\right)$, as shown in Fig. $8(\mathrm{~b})$. The fatigue crack for $\sigma_{\mathrm{w} 1}$ initiates from the stress concentration source, propagates slightly, and finally stops propagating. ${ }^{22)}$ Based on this cracking behavior for $\sigma_{\mathrm{w} 1}$, the non-propagating fatigue crack length $l_{\mathrm{w} 1}$ is regarded as the initiation size of the fatigue crack, which roughly corresponds to grain size. Namely, $l_{\mathrm{w} 2}$ and $l_{\mathrm{w} 1}$ are the stress concentration source size and the initiation size of the fatigue crack, respectively. Discussion in the next section is based on differences in initial crack length.

\subsection{Effects of Hardness on the Fatigue Limit}

Figure 9 shows a diagram of the effects of initial crack length and yield strain on the fatigue limit analyzed with the Dugdale model. ${ }^{27)}$ According to Fig. 9, assuming that the yield strain is proportional to hardness, the fatigue limit increases with increasing hardness, particularly when the initial crack length is short. The effect of hardness on the

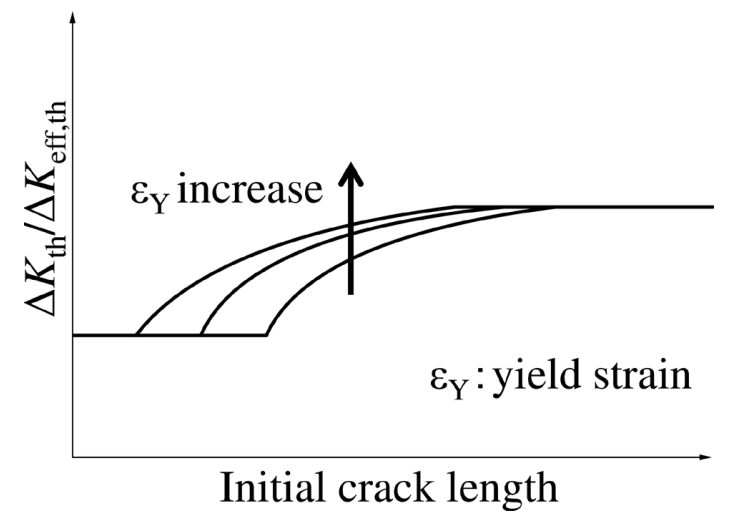

Fig. 9. Effect of yield strain on relationship between $\Delta K_{\text {th }}$ and initial crack length. ${ }^{25)}$ fatigue limit increment decreases with increasing initial crack length. Note that, as discussed in the previous section, again the initial crack lengths at $\sigma_{\mathrm{w} 1}$ and $\sigma_{\mathrm{w} 2}\left(l_{\mathrm{w} 1}\right.$ and $\left.l_{\mathrm{w} 2}\right)$ are the initiation length of the fatigue crack and the size of the stress concentration source, respectively. In the case where the fatigue limit corresponds to $\sigma_{\mathrm{w} 2}$ and its $l_{\mathrm{w} 2}$ is infinitely large, the effect of hardness does not affect the fatigue limit, as shown in Fig. 10(a). However, in fact, as shown in Fig. 10(b), the increase in hardness increases the transition curvature, $1 / \rho_{0}$, which is the intersection between the lines of $\sigma_{\mathrm{w} 1}$ and $\sigma_{\mathrm{w} 2}$. Although the size of the stress concentration source is a finite value in reality, $l_{\mathrm{w} 2}$ is larger than $l_{\mathrm{w} 1}$ as long as the size of the stress concentration source is the same. Therefore, the effect of hardness on $\sigma_{\mathrm{w} 2}$ is smaller than that on $\sigma_{\mathrm{w} 1}$, as shown in Fig. 11(a), indicating that $1 / \rho_{0}$ increases with increasing hardness as shown in Fig. 11(b).

These considerations can provide the following insights into the effects of the shape of the stress concentration source on the fatigue limits of $\mathrm{S} 45 \mathrm{C}(\mathrm{A})$ and $\mathrm{S} 45 \mathrm{C}(\mathrm{QT})$. The fatigue limit of $\mathrm{S} 45 \mathrm{C}(\mathrm{A})$ with relatively low hardness is dominated by $\sigma_{\mathrm{w} 2}$ irrespective of stress concentration source shape (i.e., whether a drill hole or an FIB notch). Thus, the fatigue limit does not depend on the curvature of the stress concentration source. In contrast, S45C(QT) is relatively hard, and thus, the curvature of the drill hole is in the region for $\sigma_{\mathrm{w} 1}$ because of increase in $1 / \rho_{0}$. On the other hand, the FIB notch that is sharper than the drill hole provides a fatigue limit which is closer to or in the region

a)

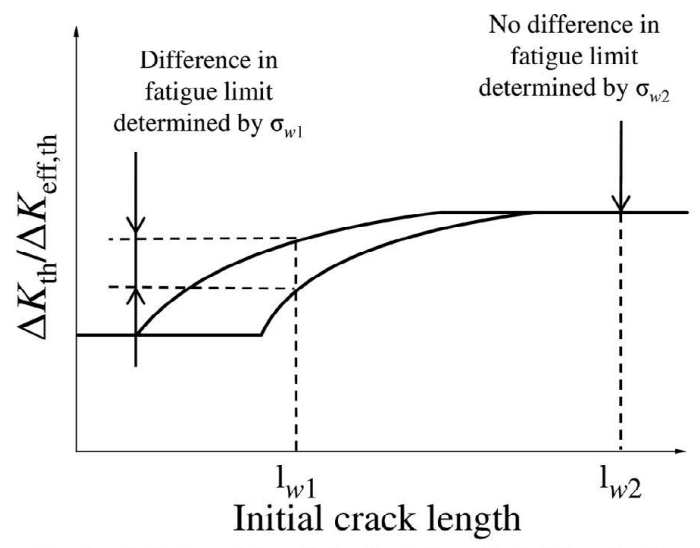

$1_{w 1}, 1_{w 2}:$ Initial crack length for the fatigue limit determined by $\sigma_{w 1}, \sigma_{w 2}$

b)

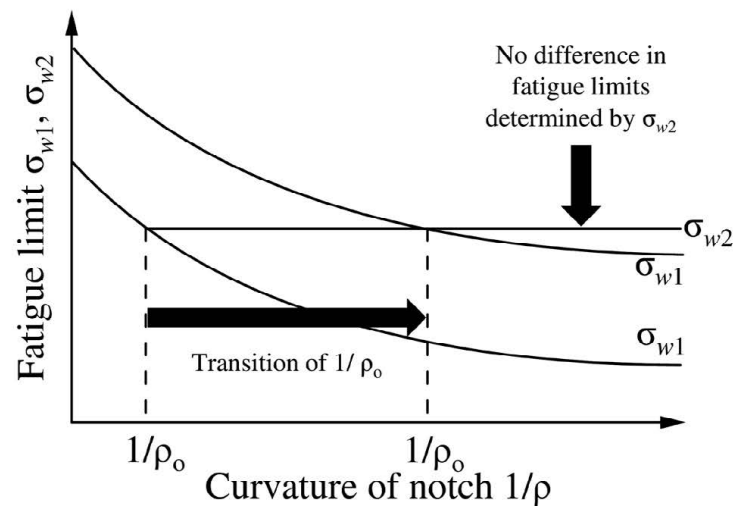

Fig. 10. Explanation for the transition of $1 / \rho_{0}$ in ideal case. a) There is the effect of hardness on $1_{w 1}$, though no effect of hardness on $1_{w 2}$. b) According to a), $1 / \rho_{\mathrm{o}}$ is affected by the hardness. 
a)

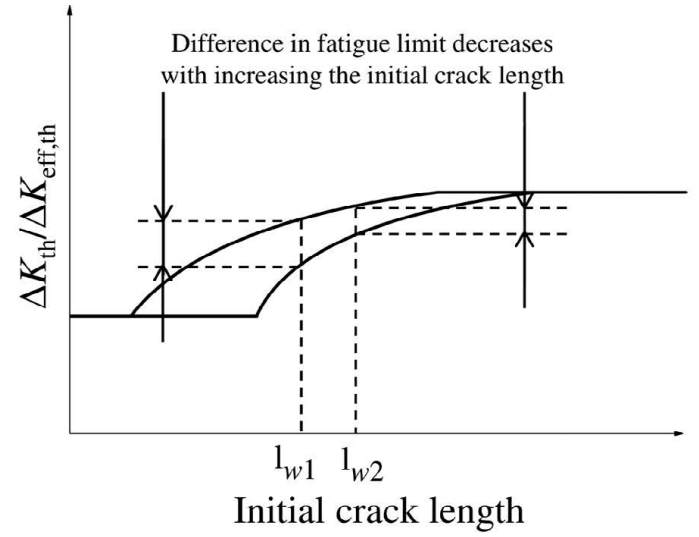

$1_{w 1}, 1_{w 2}:$ Initial crack length for the fatigue limit determined by $\sigma_{w 1}, \sigma_{w 2}$

b)

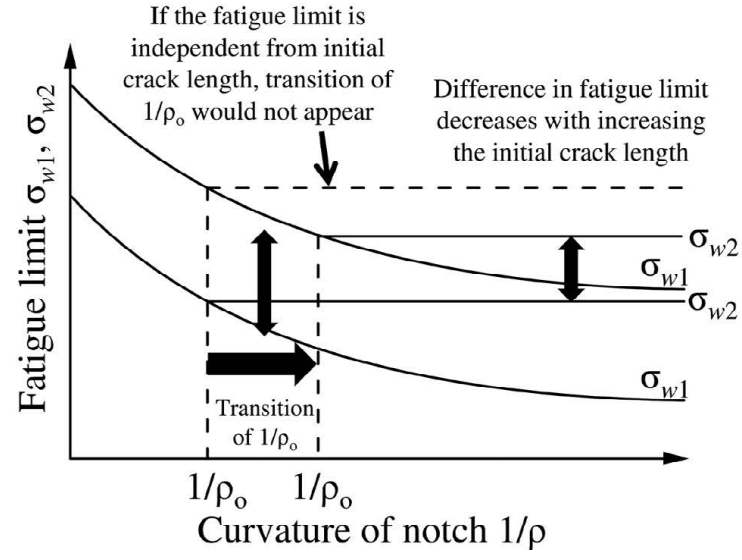

Fig. 11. a) The effect of hardness on $1_{w 1}$ is larger than that of $1_{w 2}$. b) According to a), $1 / \rho_{\mathrm{o}}$ is affected by the hardness.

of $\sigma_{\mathrm{w} 2}$. Namely, the drill hole and FIB notch at the fatigue limit of $\mathrm{S} 45 \mathrm{C}(\mathrm{A})$ are regarded as the ideal pre-crack, in contrast, the drill hole at the fatigue limit of S45C(QT) cannot be regarded as the ideal pre-crack because of an increase in $1 / \rho_{0}$. These facts indicate that evaluation of fatigue limit of pre-cracked high strength steels such as S45C(QT) requires a quite sharp stress concentration source. From the viewpoint of notch sharpness, the FIB notch is obviously sharper than the drill hole, and thus, is available in a wide strength range for the evaluation of the fatigue limit of the pre-cracked steel specimens.

\subsection{Proposal of How to Consider Notch Sensitivity}

As mentioned in the introduction part, fatigue limit of relatively low-strength steels increases linearly with increasing tensile strength. In contrast, the fatigue limit of high-strength steels increases mildly or even decreases with increasing tensile strength. This characteristic tensile strength dependence is referred to as notch sensitivity. ${ }^{13,28)}$ Figure 12 shows a schematic of notch sensitivity based on previous results. ${ }^{13,28)}$ The tendency from Phase 1 to Phase 2 is explained from the viewpoint of sensitivity to stress concentration sources such as inclusions. However, the tendency of Phase 3 requires a different interpretation. In this section, we consider damage evolution phenomena to explain the decrease in fatigue limit with increasing tensile strength (Phase 3). Damage evolution phenomena are intrinsically caused by dislocation slips or decohesion of an atomic plane or interface. In other words, only plastic deformation and brittle-like cracking can cause damage evolution

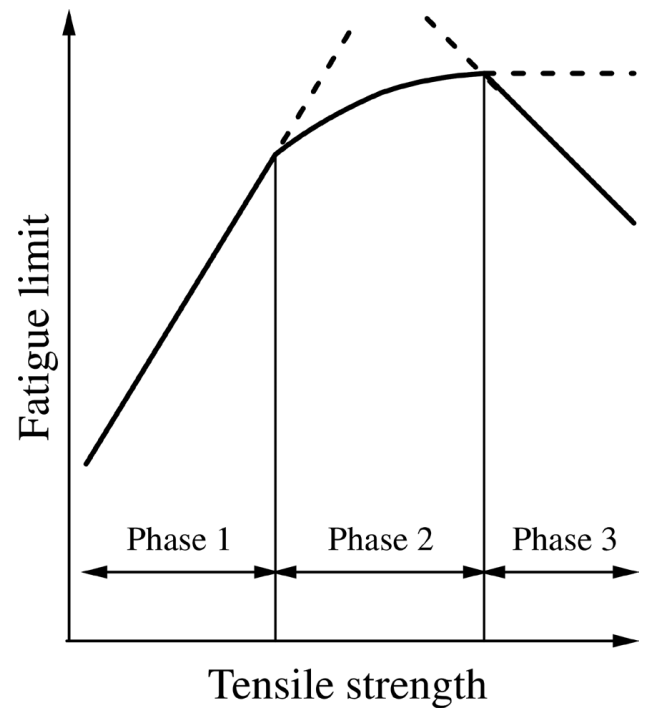

Fig. 12. Schematic diagram of notch sensitivity (the tensile strength dependence of fatigue limit).

through damage initiation and growth. Noting only the damage growth process, damage growth mechanisms associated with plastic deformation are classified into two cases: (1) a fatigue crack blunting and re-sharpening mechanism through formation of a cyclic plastic zone at the crack tip, ${ }^{24)}$ and (2) micro-void formation and its coalescence with the crack. In discussing the fatigue limit, the former mechanism is particularly important. The cyclic plastic zone remains even after fatigue crack growth, preventing fatigue crack opening through a reduction in effective stress at the crack tip. This is referred to as plasticity-induced crack closure, ${ }^{24)}$ which is a major factor inducing fatigue crack non-propagation; namely, this is a crucial reason for the presence of a fatigue limit. Plasticity-induced crack closure has been investigated by elastic-plastic analysis in continuum bodies. Since plastic strain distribution at a crack tip is obtained from continuum mechanics, fatigue crack propagation length can be estimated from the obtained cyclic displacement at the crack tip. In this study, this analytical methodology is referred to as the continuum mechanics approach. Note also that the viewpoint of brittle-like cracking is the other crucial aspect in considering fatigue crack growth mechanisms. In fact, fatigue crack growth in some high-strength materials has been reported to stem from brittle-like cracking at a crack tip. ${ }^{29)}$ When brittle-like cracking is considered for fatigue crack growth, we must discuss effects of interfaces in a noncontinuum model. Here, the consideration of microstructural effects on fatigue crack growth is referred to as the materials science approach. The present analytical results based on the Dugdale model ${ }^{27)}$ are categorized as the continuum mechanics approach. However, the analytical result shown in Fig. 9 does not explain the fact that the fatigue limit decreases with increasing tensile strength. Namely, the materials science approach, including consideration of decohesion along an interface, is indispensable in explaining the decrease in the fatigue limit with tensile strength. Here, we revisit the experimental results obtained in present and previous results. ${ }^{9}$ Since $\mathrm{S} 45 \mathrm{C}(\mathrm{A})$ with the drill hole did not show a significant difference from that of $\mathrm{S} 45 \mathrm{C}(\mathrm{A})$ with the FIB notch, both cases were considered to be in Phase 1 . In 
contrast, the difference in fatigue limit between $\mathrm{S} 45 \mathrm{C}(\mathrm{QT})$ with the drill hole and with the FIB notch is explained by the continuum mechanics approach, indicating that the results belong to Phase 2. However, note here that the critical hardness for transition from Phase 2 to Phase 3 would depend on test conditions such as the stress ratio and hydrogen environment. ${ }^{30-32)}$ Hence, the present results and associated continuum mechanics discussion indicate the requirement for the continuum mechanics approach coupled with the materials science approach in designing the fatigue limit of high-strength steels. This is particularly important for utilizing robust and high-specific-strength materials under the severe conditions recently demanded of them.

\section{Conclusion}

In this study, we discussed the effects of stress concentration source shape on the fatigue limit of a high-strength, quenched, and tempered martensitic steel. In addition, effectiveness of the FIB notch was validated for precise evaluation of the fatigue limit of high-strength steels. Our conclusions are as follows.

(1) The fatigue limit of the $\mathrm{S} 45 \mathrm{C}(\mathrm{QT})$ specimen with the small drill hole was $100 \mathrm{MPa}$ higher than that of the specimen with the FIB notch. This difference stems from the transition of $\rho_{0}$, which is the transition curvature, from $\sigma_{\mathrm{w} 1}$ to $\sigma_{\mathrm{w} 2}$ (shown in Fig. 2).

(2) The effect of a small drill hole on the fatigue limit in $\mathrm{S} 45 \mathrm{C}(\mathrm{QT})$ is not the same as that of a pre-crack, whereas its effect in $\mathrm{S} 45 \mathrm{C}(\mathrm{A})$ is the same as that of a pre-crack. In contrast, the effect of an FIB notch on the fatigue limit can be regarded as that of a pre-crack even in $\mathrm{S} 45 \mathrm{C}(\mathrm{QT})$. This fact indicates that an FIB notch can be used to evaluate the effect of a pre-crack on the fatigue limit in a relatively wide strength range compared to using a small drill hole.

(3) The fatigue crack growth model based on plastic deformation at a crack tip explains crack propagation and non-propagation behavior in the case where the fatigue limit increases with increasing tensile strength (Phase 1 and Phase 2 in Fig. 12). However, the plasticity-based model cannot provide a reasonable explanation for the fact that the fatigue limit decreases with increasing tensile strength in highstrength steels (Phase 3). Assuming that damage evolution arises only from plasticity and brittle cracking, the present discussion indicates that a brittle-like cracking model, such as the decohesion of an interface at a crack tip, is required to interpret the tendency in Phase 3.

\section{REFERENCES}

1) S. Suresh: Fatigue of Materials, The Press Syndicate of the University of Cambridge, Cambridge, (1998).

2) G. T. Gray, A. W. Thompson and J. C. Williams: Metall. Mater. Trans., 16 (1985), 753

3) Y. Murakami: Metal Fatigue: Effects of Small Defects and Nonmetallic Inclusions, Elsevier, Amsterdam, (2002).

4) K. Asakura and F. Hashimoto: Mechanical Technology, Kyoritsu Shuppan, Tokyo, (1995).

5) O. R. Speich and W. C . Leslie: Metall. Trans., 3 (1972), 1043.

6) Y. Murakami and M. Endo: Mech. Eng. Publ., 1 (1986), 275.

7) Y. Murakami, S. Kodama and S. Konuma: Int. J. Fatigue, 11 (1989), 291.

8) Y. Murakami and M. Endo: Int. J. Fatigue, 16 (1994), 163.

9) J. Sakamoto, Y. Takahashi, Y. Aono and H. Noguchi: J. Test. Eval., 29 (2013), 1.

10) A. L. Hutson, S. K. Jha, W. J. Porter and J. M. Larsen: Int. J. Fatigue, 62 (2014), 1.

11) M. J. Caton, R. Johnm, W. J. Proter and M. E. Burba: Int. J. Fatigue., 38 (2012), 36.

12) A. Roiko and J. Solin: Int. J. Fatigue, 62 (2014), 154.

13) M. F. Garwood: Interpretations of Tests and Correlation with Service, Correlation of Laboratory Tests and Service Performance, American Society for Matals, OH, (1951), 1.

14) H. Nisitani, T. Ogata and M. Endo: Trans. Jpn. Soc. Mech. Eng., Ser. A, 50 (1984), 1104.

15) Y. Murakami, M. Takada and T. Toriyama: Int. J. Fatigue, 20 (1997), 661.

16) H. Nisitani: J. Jpn. Soc. Mech. Eng., 11 (1968), 947.

17) C. E. Inglis: Trans. Inst. Naval Archit., 55 (1913), 219.

18) H. Noguchi and Y. Aono: J. Jpn. Soc. Mech. Eng. Ser. A, 61 (1995), 2044.

19) T. Matsueda and H. Noguchi: Procedia Eng., 10 (2011), 1023.

20) N. J. Wadsworth: Philos. Mag., 6 (1961), 397.

$21)$ R. A. Smith and K. J. Miller: Int. J. Mech. Sci., 20 (1978), 201.

22) K. Takao and H. Nisitani: J. Soc. Mater. Sci., 39 (1987), 1060.

$23)$ N. E. Frost and D. S. Dugdale: J. Mech. Phys. Solids, 6 (1958), 92.

24) W. Elber: ASTM Spec. Tech. Publ., 486 (1971), 230.

25) Y. Murakami and M. Endo: The Behaviour of Short Fatigue Cracks, EGF Publ.1, eds. by K. J. Miller and E. R. de los Rios, Mech. Eng. Pub., London, (1986), 275.

26) N. Fukumura, T. Suzuki, S. Hamada, K. Tsuzaki and H. Noguchi: Eng. Fract. Mech., 35 (2015), 168.

27) D. S. Dugdale: J. Mech. Phys. Solids, 8 (1960), 100.

28) M. J. Peet, P. Hill, M. Rawson, S. Wood and H. K. D. H. Bhadeshia: Mater. Sci. Technol., 27 (2011), 119.

29) J. P. Benson and D. V. Edmonds: Met. Sci., 12 (1978), 223.

30) T. Miyazaki, H. Noguchi and K. Ogi: Int. J. Fract., 129 (2004), 21.

31) S. Hamada, T. Kinoshita, K. Morishige, K. Hayashi, T. Ishina and H. Noguchi: Int. J. Fatigue, 56 (2013), 86.

32) S. Ishihara, K. Shiozawa, K. Miyao and H. Fukuchi: Trans. Jpn. Soc. Mech. Eng. A, 56 (2008), 224. 